\title{
Чувствительность к импульсным электрофизическим воздействиям энергонасыщенных соединений на основе высокодисперсного кремния и нанопористого кремния
}

\author{
(C) Г.Г. Зегря ${ }^{1}$, Г.Г. Савенков ${ }^{2}$, В.А. Морозов ${ }^{3}$, А.Г. Зегря ${ }^{1}$, Н.В. Улин ${ }^{1}$, В.П. Улин ${ }^{1}$, \\ А.А. Лукин ${ }^{2}$, В.А. Брагин ${ }^{4}$, И.А. Оськин ${ }^{4}$, Ю.М. Михайлов ${ }^{5}$ \\ ${ }^{1}$ Физико-технический институт им. А.Ф. Иоффре Российской академии наук, \\ 194021 Санкт-Петербург, Россия \\ ${ }^{2}$ Санкт-Петербургский государственный технологический институт (технический университет), \\ 190013 Санкт-Петербург, Россия \\ ${ }^{3}$ Санкт-Петербургский государственный университет, \\ 199034 Санкт-Петербург, Россия \\ ${ }^{4}$ АО «Научно-производственное объединение „Поиск“», \\ 188662 Санкт-Петербург, Россия \\ ${ }^{5}$ Институт проблем химической фризики Российской академии наук, \\ 142432 Черноголовка, Россия \\ E-mail: Zegrya@theory.ioffe.ru, sav-georgi@yandex.ru \\ (Получена 10 октября 2016 г. Принята к печати 11 октября 2016 г.)
}

\begin{abstract}
Исследована чувствительность к воздействию сильноточного электронного пучка энергонасыщенного соединения на основе нанопористого кремния и перхлората кальция. Проведены исследования по возбуждению взрывчатых превращений с помощью высоковольтного разряда смеси пикрата калия с высокодисперсным порошком кремния, легированного бором. Показано, что под действием электронного пучка в исследованном энергонасыщенном соединении возникают режимы взрывчатого превращения (горение и взрыв). Установлена связь режимов взрывчатого превращения с плотностью энергонасыщенного соединения и напряжения пробоя (инициирования) с массовой долей порошка кремния.
\end{abstract}

DOI: 10.21883/FTP.2017.04.44342.8391

\section{1. Введение}

Кремний как горючее в энергонасыщенных соединениях и, в частности, в пиротехнических малогазовых составах применялся еще в начале 30 -х годов прошлого века [1]. Но в целом применение кремния в качестве горючего в энергетических системах было ограничено, что связано в первую очередь с трудностью его окисления даже при применении самых энергичных окислителей [2].

С развитием технологии получения высокодисперсного и нанодисперсного $(n-\mathrm{Si})$ кремния интерес к нему как к горючему резко возрос $[3,4]$ и появились многочисленные статьи в популярных и научных изданиях [5], в которых обсуждалось применение $n$-Si в различных энергонасыщенных составах. Было установлено [6], что уменьшение размера частиц кремния приводит к существенному увеличению скорости его горения и при сбалансированном содержании кислорода скорость горения наноразмерного кремния приблизительно в 2 раза выше по сравнению с кремнием микронного $(\mu-\mathrm{Si})$ размера.

C начала XXI века возрос интерес, как к перспективному типу новых энергетических материалов, к пористому кремнию (por-Si), изготавливаемому по технологии электрохимического травления монокристаллического кремния в электролитах на основе плавиковой кислоты и впервые полученному еще в 1956 г. [7]. Структура кремния, образующаяся в процессе такого травления, имеет удельную поверхность, превосходящую сотни $\mathrm{m}^{2} / \Gamma[8]$.
Размеры пор в зависимости от параметров технологического процесса лежат в диапазоне от единиц нанометров до нескольких микрометров. Такая структура приводит к необычным и уникальным свойствам por-Si, например, он может гореть в чистом виде, а в сочетании с определенными окислителями у него появляется способность к взрыву (детонации) [9-13].

Инициирование процессов горения и взрыва в чистом нанопористом кремнии или в энергонасыщенном соединении на его основе осуществляют термически (соприкосновение с нагретым до высокой температуры предметом, с помощью стандартного мостика накаливания и др.), механически (царапание, укол, удар), пропусканием высоковольтного импульса тока $[11,13,14]$, с помощью микродетонаторов, а также с помощью лазерного излучения [14].

В то же время совершенно не исследована восприимчивость энергонасыщенных соединений на основе нанопористого кремния к импульсному электронному пучку, что может быть весьма актуально в случае применения таких соединений в качестве неких энергетических источников в космических аппаратах. Можно также отметить, что декларативные заявления об инициировании горения и взрыва (виды взрывчатого превращения (ВП)) при помощи высоковольтного разряда не подкреплены фактическими данными о параметрах разряда $[13,14]$.

Поэтому цель настоящей работы заключалась в поиске ответов на обе указанные проблемы на примере 
соединения por- $\mathrm{Si}$ - окислитель (перхлорат кальция $\left.\left(\mathrm{Ca}\left(\mathrm{ClO}_{4}\right)_{2}\right)\right)$ и смеси высокодисперсного порошка (размер частиц до 5 мкм), изготовленного из пластины монокристаллического кремния, легированного бором до $10^{19} \mathrm{~cm}^{-3}$, с пикратом калия $\left(\mathrm{C}_{6} \mathrm{H}_{2}\left(\mathrm{NO}_{2}\right)_{3} \mathrm{OK}\right)$ (размер частиц $\sim 100$ мкм).

\section{2. Экспериментальная часть}

\section{1. Получение энергонасыщенной композиции por-Si-перхлорат кальция}

Нанопористый кремний образуется путем самоорганизующегося процесса электрохимического травления высоколегированных (с концентрацией свободных носителей заряда $\left.10^{18}-10^{20} \mathrm{~cm}^{-3}\right)$ монокристаллов кремния во фторсодержащих электролитах $[8,15]$. Спонтанно возникающая на поверхности раздела кристалл/электролит система дискретных пятен электрохимической реакции дает начало протяженным ветвящимся каналам (порам), прорастающим в объем кристалла. Формирующиеся при этом однородные массивы наноразмерных каналов (пор), распространяясь в объем кристалла, оставляют за собой систему связанных перегородок, толщина которых сопоставима с толщиной слоя объемного заряда в исходном полупроводнике и составляет единицы нанометров $[15,16]$. Поперечные размеры каналов пор в нанопористом кремнии варьируются обычно в пределах от 5 до 30 нм [8] (с точки зрения современной классификации пористого кремния в нашей статье речь идет о мезопористом кремнии).

Метод получения мезопористого кремния с технической точки зрения достаточно прост. Схематическое изображение реактора электрохимического травления высоколегированного монокристаллического кремния в HF-содержащих электролитах приведено на рис. 1 работы $[8]$.

Основные структурные характеристики мезопористого кремния, образующегося в ходе процесса электрохимического травления высоколегированного монокристаллического кремния, такие как поперечные размеры пор, толщины разделяющих их перегородок и соответственно степень пористости, определяются прежде всего типом проводимости и уровнем легирования исходного монокристаллического кремния, химическим составом электролита и величиной плотности анодного тока [8]. В меньшей степени структурные параметры мезопористого кремния зависят от кристаллографической ориентации поверхности исходных пластин монокристаллического кремния.

\section{2. Облучение энергонасыщенного соединения por-Si-перхлорат кальция сильноточным электронным пучком}

Исследование чувствительности энергонасыщенного соединения por-Si-перхлорат кальция к сильноточному

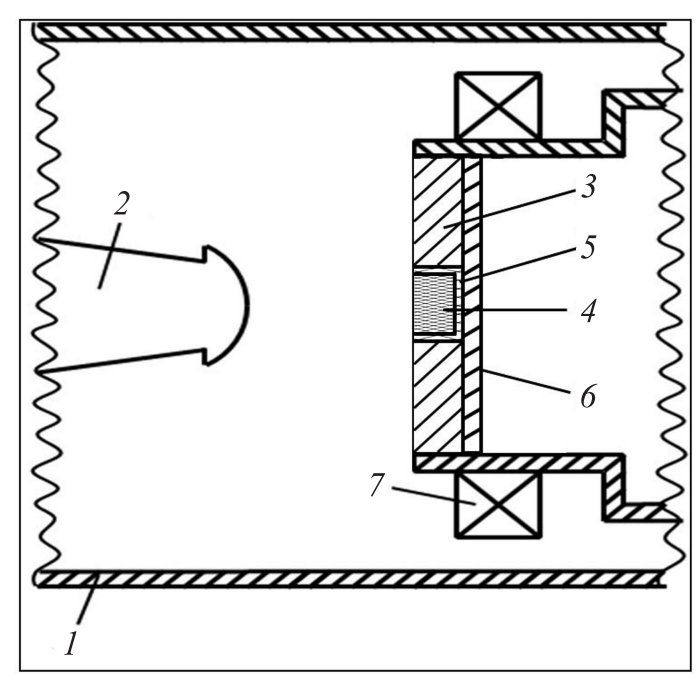

Рис. 1. Экспериментальная схема облучения пучком электронов образца: 1 - вакуумная камера, 2 - катод, 3 - стальное кольцо, 4 - энергонасыщенный состав, 5 - колпачок, $6-$ подложка, 7 - пояс Роговского.

электронному пучку (СЭП) проводили на ускорителе электронов ГКВИ-300, позволяющему получать импульсные пучки со средней энергией электронов 250 кэВ и длительностью $t_{b}$ импульса напряжения на полувысоте $30-50$ нс. Схема облучения образца пучком, представлена на рис. 1. Энергонасыщенная композиция помещалась в латунный колпачок высотой 3 мм и внутренним диаметром 4.5 мм. Внешний диаметр стального кольца, в которое устанавливался колпачок с составом, 30 мм. Расстояние между катодом и стальным кольцом 4 мм, диаметр пучка 8 мм.

В работе применялись три разновидности экспериментальной схемы, представленной на рис. 1.

Схема 1. На образец действовал СЭП и катодный факел (КФ) (катодный факел - взрыв микронеоднородностей на катоде из-за лавинообразного нарастания тока, вызванного джоулевым нагревом эмиттера [17]). Скорость пучка $\sim 0.5 C$ ( $C$ - скорость света $)$, скорость КФ $\sim 150$ км/с [18], но катодный факел обладает большей плотностью по сравнению с СЭП и имеет высокую температуру $(\sim 2500 \mathrm{~K})$, поэтому, если для возбуждения взрывчатых превращений (ВП) (горения или детонации) энергонасыщенных материалов (ЭНМ) энергии пучка не хватает, то добавочная энергия за счет КФ может привести к их срабатыванию $[19,20]$.

Схема 2. Катодный факел отсекался при помощи алюминиевой фольги толщиной 15 мкм, устанавливаемой вплотную на стальное кольцо. При этом, естественно, терялась часть энергии электронного пучка.

Схема 3. Катодный факел отсекался при помощи двух слоев алюминиевой фольги толщиной 15 мкм каждый, устанавливаемых вплотную на стальное кольцо. При этом энергия электронного пучка уменьшалась более значительно, чем в схеме 2. 
Таблица 1. Характеристики энергонасыщенной композиции

\begin{tabular}{|c|c|c|c|}
\hline $\begin{array}{c}\text { № схемы } \\
\text { эксперимента }\end{array}$ & $\begin{array}{c}\text { Массовая } \\
\text { доля por-Si }\end{array}$ & $\begin{array}{c}\text { Масса } \\
\text { образца, мг }\end{array}$ & $\begin{array}{c}\text { Плотность } \rho_{0}, \\
\Gamma / \mathrm{cm}^{3}\end{array}$ \\
\hline 1 & $28.5-28.6$ & $34-35$ & $0.786-0.815$ \\
\hline 2 & $16-16.1$ & $58-59$ & $1.30-1.35$ \\
\hline 3 & $12.1-13.0$ & $91-92$ & $2.04-2.14$ \\
\hline
\end{tabular}

Характеристики энергонасыщенного соединения для каждой схемы эксперимента приведены в табл. 1.

Широкий диапазон плотностей энергонасыщенных композиций, представленных в табл. 1, объясняется желанием исследования влияния плотности на чувствительность к действию СЭП. Связано это с двумя причинами. Во-первых, увеличение плотности ЭНМ приводит к увеличению его энергетических характеристик и одновременному снижению чувствительности к внешним воздействиям. Особенно (и это вторая причина) с увеличением плотности, резко должна уменьшаться восприимчивость к действию СЭП. Такое гипотетическое уменьшение чувствительности объясняется тем, что глу-

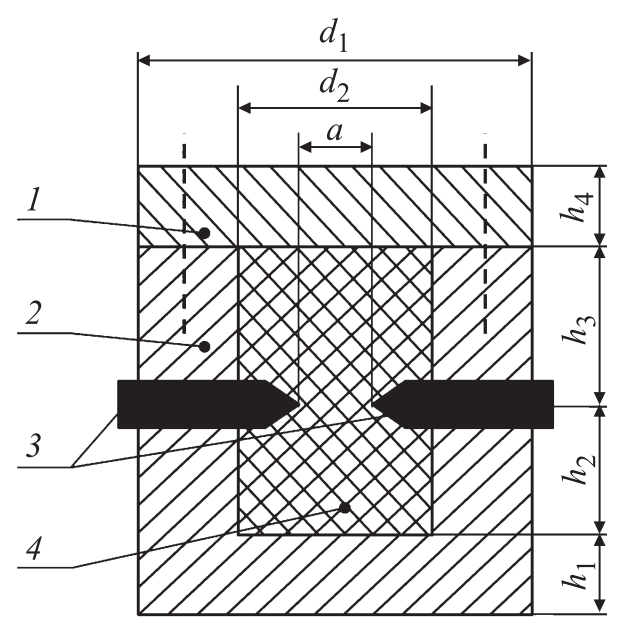

Рис. 2. Контейнер с энергонасыщенной смесью: 1 - крышка, 2 - корпус, 3 - электроды, 4 - энергонасыщенная смесь $\mathrm{Si}+\mathrm{C}_{6} \mathrm{H}_{2}\left(\mathrm{NO}_{2}\right)_{3} \mathrm{OK}$ (штриховыми линиями показаны места крепления крышки).

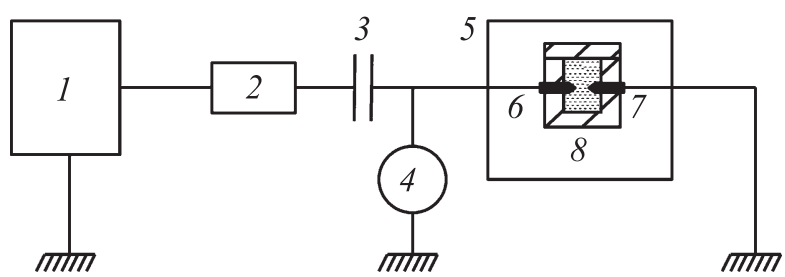

Рис. 3. Электрическая схема проведения эксперимента: 1 - источник высокого напряжения, 2 - зарядное сопротивление, 3 - зарядная емкость $(0.5$ мкФ), 4 - киловольтметр, 5 - камера, 6 - высоковольтный электрод, 7 - заземленный электрод, 8 - контейнер с энергонасщенной смесью. бина максимального энерговыделения электронного пучка, а также экстраполированная глубина пробега электронов зависят от плотности вещества [21]. Чем меньше плотность, тем выше значение глубины максимального энерговыделения и пробега электронов и выше вероятность возбуждения взрывчатых превращений, поскольку приповерхностные слои испаряются, а чем глубже проникнет пучок, тем больше так называемых „горячих“ точек (очагов инициирования) он создаст. Их нагрев до критической температуры и приводит к быстрой экзотермической реакции (взрывчатому превращению).

Смесь $\mathrm{Si}+\mathrm{C}_{6} \mathrm{H}_{2}\left(\mathrm{NO}_{2}\right){ }_{3} \mathrm{OK}$ (варьировалась массовая доля порошка кремния, масса пикрата во всех экспериментах составляла $m_{C}=480$ мг) перемешивалась до получения однородного цвета и помещалась в корпус контейнера (рис. 2) из полиметилметакрилата (ПММА).

Внешний диаметр корпуса контейнера $d_{1}=20 \mathrm{MM}$, внутренний диаметр $d_{2}=10 \mathrm{MM}$, толщина стенок и донышка контейнера $h_{1}=5$ мм. Глубина контейнера $\left(h_{2}+h_{3}\right)=10$ мм, на высоте $h_{2}=5$ мм от дна корпуса в стенке корпуса выполнены 2 отверстия под стальные остроконечные электроды диаметром 3 мм. Корпус контейнера закрывается крышкой из ПММА толщиной $h_{4}=5$ мм, которая крепится к корпусу двумя винтами. Расстояние между электродами $a=3$ мм.

\section{3. Инициирование горения смеси $\mathrm{Si}+\mathrm{C}_{6} \mathrm{H}_{2}\left(\mathrm{NO}_{2}\right)_{3} \mathrm{OK}$ высоковольтным разрядом}

Электрическая схема проведения эксперимента представлена на рис. 3 .

При подаче высоковольтного импульса напряжения через зарядную емкость между электродами возникает искровой пробой и происходит возбуждение ВП в энергонасыщенной смеси. Инициирование взрыва в такой смеси происходит в результате совместного действия нагрева и ударной волны [18].

Пикрат калия является типичным диэлектриком, напряжение пробоя (и соответственно инициирования) в описанных условиях $U_{i g n}=9.5-9.7 \mathrm{\kappa}$, напряжение пробоя порошка кремния при плотности запрессовки $\rho_{0}=1.7 г / \mathrm{cm}^{3} U_{b}=2.0-2.2 \kappa \mathrm{B}$.

\section{3. Результаты экспериментов и их обсуждение}

\section{1. Результаты инициирования энергонасыщенного соединения por-Si $+\mathrm{Ca}\left(\mathrm{ClO}_{4}\right)_{2}$ с помощью СЭП}

В результате воздействия СЭП на энергонасыщенное соединение por- $\mathrm{Si}+\mathrm{Ca}\left(\mathrm{ClO}_{4}\right)_{2}$ по экспериментальной схеме 1 были получены следующие результаты. Композиция por- $\mathrm{Si}+\mathrm{Ca}\left(\mathrm{ClO}_{4}\right)_{2}$ в колпачке полностью выгорала, на катоде наблюдалось термическое пятно (рис. 4, a), которое практически занимало 20-90\% поверхности 


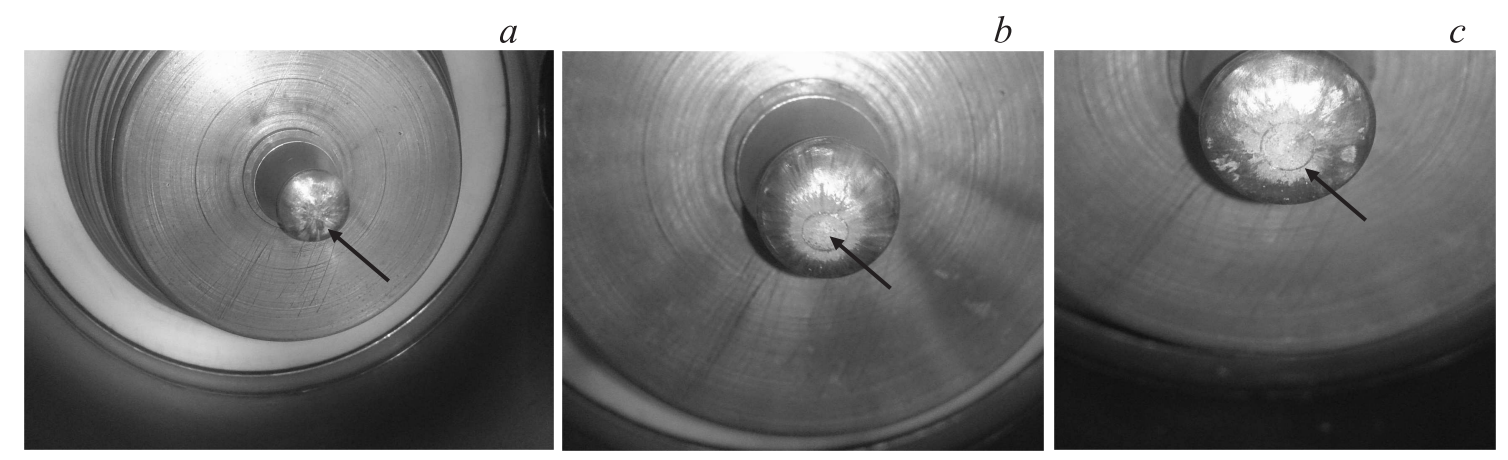

Рис. 4. Термическое пятно (указано стрелкой) $(a)$ и отпечатки колпачка (указано стрелкой) $(b, c)$ на катоде после воздействия на образец СЭП +КФ.

катода. Можно отметить, что осциллограммы напряжения с помощью пояса Роговского ни разу не удалось зафиксировать, что с некоторой долей вероятности можно интерпретировать как результат, свидетельствующий о неких посторонних электрических полях, которые могли появиться, например, вследствие хемоионизации пламени [22] или внутри горящей гетерогенной конденсированной системы.

Воздействие СЭП на энергонасыщенную композицию через алюминиевую фольгу толщиной 15 мкм (экспериментальная схема 2) также приводило к возбуждению ВП. Однако режим ВП [23] в этом случае был существенно выше по уровню мощности и параметрам (например, это мог быть режим конвективного горения или низкоскоростная детонация). На такое развитие процесса указывает (кроме термического пятна) отпечаток колпачка на катоде (рис. 4,c). Размер термического пятна был практически в 2 раза меньше, чем в случае экспериментальной схемы 1.

Результатом воздействия СЭП на энергонасыщенную композицию por- $\mathrm{Si}+\mathrm{Ca}\left(\mathrm{ClO}_{4}\right)_{2}$ по экспериментальной схеме 3 (через два слоя фольги толщиной 15 мкм каждый) было следующее. На катоде, так же как и в случае схемы 2, был отпечаток колпачка, но термическое пятно по размерам было существенно больше, чем в схеме 2. Кроме того, в оправке, удерживающей стальное

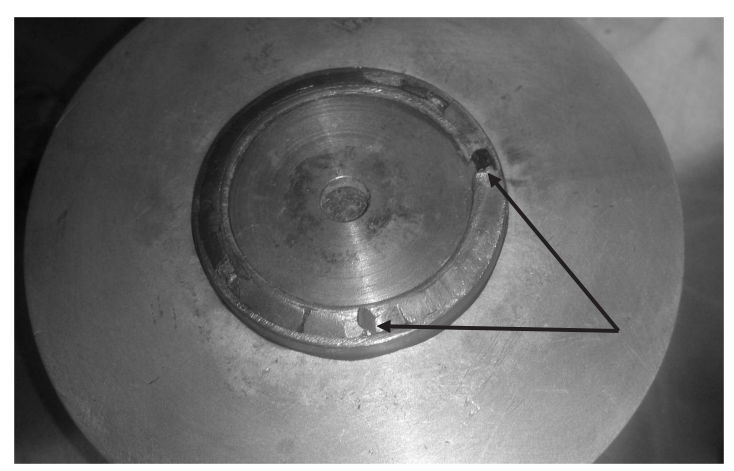

Pис. 5. Фрагменты разрушения (указаны стрелками) оправки, удерживающей стальное кольцо. кольцо, наблюдались фрагменты разрушения по всей ее окружности (рис. 5). Все это указывало на то, что режим взрывчатого превращения по своим параметрам превосходил режим ВП в схеме 2.

Как отмечалось выше, глубина, на которой происходит максимальное энерговыделение пучка, а также экстраполированная глубина пробега электронов зависят от плотности вещества. Таким образом, чем меньше плотность, тем выше значения указанных глубин и соответственно выше вероятность возбуждения ВП, поскольку, чем глубже проникнет пучок, тем больше очагов инициирования он создаст, нагрев которых до критической температуры и приводит к одному из режимов взрывчатого превращения [24]. Из этого следует, что исследованной композиции por- $\mathrm{Si}+\mathrm{Ca}\left(\mathrm{ClO}_{4}\right)_{2}$, хватает даже небольшого количества очагов инициирования, чтобы произошло взрывчатое превращение.

Таким образом, в результате исследования было установлено, что энергонасыщенная композиция por $-\mathrm{Si}+\mathrm{Ca}\left(\mathrm{ClO}_{4}\right)_{2}$ имеет очень высокую чувствительность к воздействию сильноточного электронного пучка.

\section{2. Результаты возбуждения ВП смеси $\mathrm{Si}+\mathrm{C}_{6} \mathrm{H}_{2}\left(\mathrm{NO}_{2}\right)_{3} \mathrm{OK}$ высоковольтным разрядом}

Результаты экспериментов по инициированию взрывчатых превращений в энергонасыщенной смеси $\mathrm{Si}+\mathrm{C}_{6} \mathrm{H}_{2}\left(\mathrm{NO}_{2}\right)_{3} \mathrm{OK}$ приведены в табл. 2 .

В работе [25] были получены результаты по электрическому пробою в прессованном азиде свинца (типичном инициирующем взрывчатом веществе). На основании этих результатов автор утверждал, что пробой происходит по воздушным каналам между кристаллами вещества. Поэтому в рамках настоящей работы были проведены эксперименты по пробою воздушного промежутка между электродами.

Результаты экспериментов были следующие: напряжение пробоя воздушного промежутка шириной 3 мм между остроконечными электродами составляет $U_{b}=7.9-8.1 \mathrm{\kappa B}$. Полученный результат дает основание утверждать, что пробой энергонасыщенной смеси 
Таблица 2. Результаты экспериментов

\begin{tabular}{|c|c|c|c|c|}
\hline № & $\begin{array}{l}\text { Массовая } \\
\text { доля } \mu-\mathrm{Si}\end{array}$ & $\rho_{0}, \Gamma / \mathrm{cm}^{3}$ & $U, \kappa \mathrm{B}$ & $\begin{array}{c}\text { Количество осколков } \\
\text { контейнера }\end{array}$ \\
\hline 1 & 0 & 0.72 & $9.5-9.6$ & Множество мелких \\
\hline 2 & 3 & 0.7 & $9.0-9.2$ & $18-20$ (5-6 крупных) \\
\hline 3 & 4 & 0.69 & $7.1-7.3$ & $18-19$ (4-5 крупных) \\
\hline 4 & 4.5 & 0.68 & $6.7-6.9$ & 17-18 (3-4 крупных) \\
\hline 5 & 5 & 0.72 & $5.8-6.0$ & 16-17 (множество мелких) \\
\hline 6 & 6.8 & 0.73 & $4.5-4.6$ & 13-14 (множество мелких) \\
\hline 7 & 8.6 & 0.73 & $3.5-3.7$ & $\begin{array}{l}7 \text { (1-2 крупных } \\
\text { и множество мелких) }\end{array}$ \\
\hline
\end{tabular}

Примечание. 1) крупные осколки - один из размеров которых $\geq 5$ мм; 2) мелкие осколки - размеры которых меньше 0.5 мм.

$\mathrm{Si}+\mathrm{C}_{6} \mathrm{H}_{2}\left(\mathrm{NO}_{2}\right)_{3} \mathrm{OK}$ в наших экспериментах происходил не по воздушному каналу между частицами смеси.

Дальнейший анализ результатов, представленных в табл. 2, показал.

1. Пробивное напряжение (и соответственно напряжение инициирования) уменьшается с увеличением массовой доли $\mu$-Si. Необходимо отметить следующий факт. В работах $[26,27]$ приведены результаты инициирования ВП высоковольтным электрическим разрядом взрывчатого вещества FOX-7 в смеси с различными порошковыми проводящими добавками. Оказалось, что добавка 15-20\% массовой доли (что существенно выше, чем добавка порошка кремния в настоящей работе) нанои микроразмерного порошка алюминия не приводит к взрывчатым превращениям в смеси. В работе [26] это объяснялось образованием окисной пленки на поверхности частиц, а в работе [27] отсутствием достижения предела поверхностной перколяции.

2. Отсутствие резкого уменьшения напряжения пробоя при увеличении концентрации $\mu$-Si указывает на отсутствие перколяционного перехода, который должен наблюдаться вблизи объемной критической концентрации полупроводник $x_{c}\left(x_{c}=0.29\right.$ [26]). В нашем случае объемная доля $\mu$-Si при максимальной массовой концентрации 0.086 равна $x_{c}=0.045$ (расчеты проведены по формулам, полученным в $[27,28])$.

3. Малая добавка $\mu$-Si вначале резко замедляет процесс ВП (на что указывает малое количество осколков корпуса контейнера в целом и относительно большое количество крупных осколков), затем по мере увеличения концентрации порошка легированного кремния скорость процесса растет. Полученный результат, по нашему мнению, требует дополнительной проверки.

\section{4. Заключение}

Проведенные испытания позволяют утверждать, что энергонасыщенные соединения нанопористого кремния с окислителями обладают высокой чувствительностью к воздействию сильноточного электронного пучка. Под его воздействием в таких соединениях происходят про- цессы взрывчатого превращения, при этом чем выше плотность соединения, тем выше параметры режима ВП.

Установлено, что добавка высокодисперсного порошка кремния, легированного бором, в энергонасыщенное вещество снижает величину напряжения пробоя (инициирования). Можно предполагать, что при некоторой концентрации $\mu$-Si можно добиться существенного снижения пробойного напряжения и получить энергетические характеристики взрывчатой смеси по крайней мере не хуже характеристик исходного энергонасыщенного вещества.

Работа выполнена при поддержке РФФИ, грант № 16-29-01085 офи_м.

\section{Список литературы}

[1] В.Э. Мельников. Современная пиротехника (М., Наука, 2014). гл. 2, $480 \mathrm{c.}$

[2] А.А. Шидловский. Основы пиротехники (М., Машиностроение, 1973) ч. 1 , гл. 2, с. 15.

[3] J.T. Hedger. Propellants, Explosives, Pyrotechnics, 8, 95 (1983).

[4] E.C. Koch, D. Clement. Propellants, Explosives, Pyrotechnics, 3, 205 (2007).

[5] М.Ф. Гогуля, М.А. Бражников. Горение и взрыв. (М., ТОРУС ПРЕСС, 2009) т. 2, с. 137.

[6] B.P. Berger, B. Haas, J. Mathieu, T. Vine, T.T. Griffiths. Proc. Thirty-Third Intern., Pyrotechnics Seminar (Fort Collins, Colorado, 2006) p. 81.

[7] A.G. Cullis, L.T. Canham, P.D.J. Calcott. J. Appl. Phys. Rev., 82, 909 (1997).

[8] О.И. Ксенофонтова, А.В. Васин, В.В. Егоров, А.В. Бобыль, Ф.Ю. Солдатенков, Е.И. Теруков, В.П. Улин, Н.В. Улин, О.И. Киселев. ЖТФ, 84 (1), 67 (2014).

[9] D. Kovalev, V.Yi. Timoshenko, N. Kunzner, E. Gross, F. Koch. Phys. Rev. Lett., 87, 068301 (2001).

[10] D. Clement, J. Diener, E. Gross, N. Künzner, V. Yu., D Kovalev. Phys. Status Solidi A 202, 1357 (2005).

[11] С.К. Лазарук, А.В. Долбик, П.В. Жагиро, В.А. Лабунов, В.Е. Борисенко. ФТП, 39 (8), 917 (2005).

[12] Ю.М. Михайлов, В.А. Гаранин, Ю.В. Ганин, Е.К. Гончаров, Л.В. Ганина, Г.Г. Зегря. Изв. АН, Сер. хим., 10, 2400 (2010).

[13] С.К. Лазарук, А.В. Долбик, В.А. Лабунов, В.Е. Борисенко. ФТП, 41 (9), 1130 (2007).

[14] E.G. Kishilev, A. Gany. Proc. 6 Seminar New Trends in Research of Energetic Materials (Pardubice, Czech Republic, 2013) p. 197.

[15] В.П. Улин, Н.В. Улин, Ф.Ю. Солдатенков, А.В. Семенов, А.В. Бобыль. ФТП, 48 (9), 1243 (2014).

[16] A. Bobyl, S. Konnikov, D. Sakseev, F. Soldatenkov, G. Tereschenko, V. Ulin. Ind. Eng. Chem. Res., 46, 2263 (2007).

[17] Г.К. Карцев, Г.А. Месяц, Д.И. Проскуровский, В.П. Ротштейн, Г.Н. Фурсей. ДАН СССР, 192 (2), 309 (1970).

[18] V.A. Morozov, A.A. Lukin, G.G. Savenkov, I.A. Oskin. Proc. Intern. Conf. on „Stability and Control Processes“ in Memory of V.I. Zubov (2015) p. 177.

[19] В.А. Морозов, Г.Г. Савенков. Хим. физика, 32 (6), 69 (2013). 
[20] Г.Г. Савенков, В.А. Морозов, А.А. Лукин, В.А. Брагин, Г.В. Семашкин. Письма ЖТФ, 40 (6), 50 (2014).

[21] В.А. Морозов, Г.Г. Савенков, В.А. Брагин, В.М. Кац, А.А. Лукин. ЖТФ, 82 (5), 129 (2012).

[22] К.П. Станюкович. Физика взрыва (М., Наука, 1975). c. 704 .

[23] Н.И. Кидин, В.Б. Либрович. Физика горения и взрыва, 5, 696 (1974).

[24] Л П. Орленко. Физика взрыва (М., Физматлит, 2002) т. 1, c. 832.

[25] В.В. Стеньгач. Прикл. механика и техн. физика, 1, 128 (1972).

[26] В.А. Брагин, С.А. Душенок, В.Г. Куликов, Г.Г. Савенков, Г.В. Семашкин. Хим. физика, 31 (5), 57 (2012).

[27] С.А. Рашковский, Г.Г. Савенков. ЖТФ, 83 (4), 47 (2013).

[28] В.А. Соцков. ФТП, 39 (2), 269 (2005).

Редактор Г.А. Оганесян

\section{Sensitivity of energy saturated compounds based on superfine and nanoporous silicon to the action of electrical impulses}

G.G. Zegrya ${ }^{1}$, G.G. Savenkov ${ }^{2}$, V.A. Morozov ${ }^{3}$, A.G. Zegrya ${ }^{1}$, N.V. Ulin ${ }^{1}$, V.P. Ulin ${ }^{1}$, A.A. Lukin ${ }^{2}$, V.A. Bragin ${ }^{4}$, I.A. Oskin ${ }^{4}$, Yu.M. Mikhailov ${ }^{5}$

${ }^{1}$ loffe Institute, 194021 St. Petersburg, Russia

${ }^{2}$ Saint-Petersburg State Engineering Institute

(Technical University),

190013 St. Petersburg, Russia

${ }^{3}$ Saint -Petersburg State University, 199034 St. Petersburg, Russia ${ }^{4}$ Jsc Scientific Production Association „Poisk", 188662 St. Petersburg, Russia ${ }^{5}$ Institute of Chemical Physics Problems of Russian Academy of Sciences, 142432 Chernogolovka, Russia

Abstract An energy-saturated compound based on nanoporous silicon and calcium perchlorate has been investigated from the standpoint of its sensitivity to the action of high-current electron beam. Some investigations have been performed in which explosive transformations were energized with the help of highvoltage discharge in potassium picrate mixed with superfine silicon power doped by boron. It was shown that under the action of electron beam there appeared some explosive transformations (burning and explosion). There has been determined that explosive transformations relate to the density of energy-saturated compound and breakdown voltage (initiation) does to the mass fraction of silicon powder. 